\title{
Synthesis and Properties of Polysilsesquioxanes Having Ethoxysulfonyl Group as a Side Chain
}

\author{
Takahiro Gunji, Kazuki Yamamoto, Akira Tomobe, Noritaka Abe, and Yoshimoto Abe \\ Department of Pure and Applied Chemistry, Faculty of Science and Technology, Tokyo University of Science, 2641 Yamazaki, \\ Noda, Chiba 278-8510, Japan \\ Correspondence should be addressed to Takahiro Gunji, gunji@rs.noda.tus.ac.jp
}

Received 29 June 2012; Accepted 20 August 2012

Academic Editor: Yoshiro Kaneko

Copyright ( 92012 Takahiro Gunji et al. This is an open access article distributed under the Creative Commons Attribution License, which permits unrestricted use, distribution, and reproduction in any medium, provided the original work is properly cited.

Polysilsesquioxane having an ethoxysulfonyl group as a side chain was synthesized to prepare a proton-conductive film composed of a main chain of siloxane. At first, sodium 4-(2-methylallyloxy)benzenesulfonate was chlorinated with thionyl chloride. Next, hydrosilylation with trichlorosilane was carried out in the presence of platinum catalyst followed by treatment with ethanol. Finally, the hydrolytic polycondensation was carried out to provide poly(3-(4-ethoxysulfonylphenoxy)-2-methylpropyl)silsesquioxane. This polysilsesquioxane was heated to form a free-standing film that was brittle and brown in color.

\section{Introduction}

Fuel cells, which generate power using hydrogen and oxygen gases, have been a focus of recent interest due to their potential for resolving both energy and environmental problems, as they produce very little pollution and have a high power generation efficiency. In particular, polymer electrolyte fuel cells (PEFCs), which are fuel cells that utilize a proton conductive membrane as an electrolyte, are expected to have a high potential, as PEFCs can generate power at low temperature with high energy density. PEFCs are therefore suitable for miniaturization to make them suitable for home use, for portable devices, or for car batteries. The proton-conducting membrane most commonly used is a fluorine-containing polyelectrolyte film that works under moderate moisture to improve proton conductivity. PEFCs are, however, difficult to operate at high temperatures, which can lower the power-generation efficiency due to the low heat resistance of the electrolyte film.

In the previous works, a proton-conducting membrane utilizing a siloxane bond as a main chain with high heat resistance was utilized: polysilsesquioxanes having an acid group in the side chain were prepared by a sol-gel method [1-5] and then mixed with polyketone $[6,7]$, fluorine-containing polymer [8], or phosphor-containing polymer [9]. The film prepared showed high proton conductivity of approximately $10^{-2} \mathrm{~S} / \mathrm{cm}[1-3,5,7,9]$, which is higher than the perfluorotype polymer electrolyte [10]. The degradation or phase separation of organic and inorganic components is a demerit in the use of these membranes over the long term.

In our previous report, film formation was carried out by hydrolytic polycondensation and subsequent oxidation of a silane-coupling agent, which resulted in the degradation of polysiloxanes by a sulfonic acid group to give a broken film [11]. In contrast, copolymerization of a silane coupling agent having a mercapto group with 1,2-trimethoxysilylethane provided a proton-conducting film with a heat resistivity to $150^{\circ} \mathrm{C}$.

Polysilsesquioxane is useful as a framework in organicinorganic polymer hybrid material because of its high heatresistivity, high mechanical properties, and easy introduction of functional groups in the side chain. The application of polysilsesquioxanes as a PEFC membrane is limited by the degradation of the siloxane chain and gel formation by the acid groups. In order to improve this problem, a polysilsesquioxane having an arylsulfonic acid as a side chain was examined. The side chain is expected to form a stacking structure by the steric hindrance and interaction of pi electrons of an aryl group to depress the degradation of siloxane bonding by sulfonic acid. In this work, therefore, the 
synthesis of polysilsesquioxane having a sulfonic acid group from an arylsulfonic ester derivative as well as formation of the membrane was investigated according to the Scheme 1.

\section{Experimental}

2.1. Reagents. Thionyl chloride, toluene, pyridine, acetone, sodium hydroxide, and $6 \mathrm{~mol} / \mathrm{L}$ hydrochloric acid (Wako Pure Chemical Industries Ltd., reagent grade) were used as received.

Trichlorosilane (Shin-Etsu Chemical Industry, Co., Ltd.) was used as received.

Ethanol and hexane (Kanto Chemical, Co., Ltd.) were dried over calcium oxide and distilled before use.

Sodium 4-hydroxybenzenesulfonate dihydrate, 3-chloro2-methyl-1-propene, and chloroplatinic (IV) acid (Tokyo Chemical Industry Co., Ltd.) were used as received.

2.2. Synthesis of Sodium 4-(2-Methyl-2-propenoxy)benzenesulfonate. Sodium 4-(2-methyl-2-propenoxy)benzenesulfonate was synthesized according to the procedure shown in the literature [12]. Sodium 4-hydroxybenzenesulfonate dihydrate $174 \mathrm{~g}(0.75 \mathrm{~mol})$ was mixed with water $375 \mathrm{~mL}$, acetone $375 \mathrm{~mL}$, and sodium hydroxide $30.8 \mathrm{~g}(0.77 \mathrm{~mol})$ and heated to reflux for $10 \mathrm{~min}$. 3-Chloro-2-methyl-1-propene was added slowly and subjected to reflux for $24 \mathrm{~h}$, followed by recrystallization.

Yield: $104 \mathrm{~g}(80 \%)$. White crystal. ${ }^{1} \mathrm{H}$ NMR [ $\left.\delta / \mathrm{ppm}\right]$ $\left(300 \mathrm{MHz}, \mathrm{CDCl}_{3}\right) 1.84(\mathrm{~s}, 3 \mathrm{H}), 4.55(\mathrm{~s}, 2 \mathrm{H}), 5.07(\mathrm{~d}, 1 \mathrm{H})$, $5.09(\mathrm{~d}, 1 \mathrm{H}), 7.06(\mathrm{~d}, 2 \mathrm{H}, J=9.0 \mathrm{~Hz}), 7.99(\mathrm{~d}, 2 \mathrm{H}, J=9.0 \mathrm{~Hz})$. MS (ESI) $m / z=246\left[\mathrm{M}^{+}\right], 211[\mathrm{M}-\mathrm{Cl}]^{+}$.

2.3. Synthesis of 4-(2-Methyl-2-propenoxy)benzenesulfonyl Chloride. 4-(2-methyl-2-propenoxy)benzenesulfonyl chloride was synthesized according to a previously reported procedure [12]. First, $25 \mathrm{~g}(0.1 \mathrm{~mol})$ of sodium 4-(2-methyl2 -propenoxy)benzenesulfonate was mixed with thionyl chloride $11 \mathrm{~mL}(0.15 \mathrm{~mol})$, dimethylformamide $0.1 \mathrm{~mL}$, and toluene $100 \mathrm{~mL}$ and heated to $100^{\circ} \mathrm{C}$ for $12 \mathrm{~h}$. The reaction mixture was washed with water three times, followed by drying and condensation.

Yield: $23 \mathrm{~g}(80 \%)$. Colorless liquid. ${ }^{1} \mathrm{H}$ NMR $[\delta / \mathrm{ppm}]$ $\left(300 \mathrm{MHz}, \mathrm{CDCl}_{3}\right) 1.84(\mathrm{~s}, 3 \mathrm{H}), 4.55(\mathrm{~s}, 2 \mathrm{H}), 5.07(\mathrm{~d}, 1 \mathrm{H})$, $5.09(\mathrm{~d}, 1 \mathrm{H}), 7.06(\mathrm{~d}, 2 \mathrm{H}, J=9.0 \mathrm{~Hz}), 7.99(\mathrm{~d}, 2 \mathrm{H}, J=9.0 \mathrm{~Hz})$. MS (ESI) $m / z=246\left[\mathrm{M}^{+}\right], 211[\mathrm{M}-\mathrm{Cl}]^{+}$.

2.4. Synthesis of 4-(2-Methyl-3-trichlorosilylpropoxy)benzenesulfonyl Chloride. $3.0 \mathrm{~g}(13 \mathrm{mmol})$ of 7 was mixed with trichlorosilane $12 \mathrm{~mL}(0.15 \mathrm{~mol})$ and $5 \%$ 2-propanol solution of chloroplatinic acid dihydrate $0.1 \mathrm{~mL}$ and heated at $50^{\circ} \mathrm{C}$ for $12 \mathrm{~h}$ to complete the hydrosilylation. Product was recovered by condensation under reduced pressure.

Yield: $3.2 \mathrm{~g}(69 \%)$. Yellow liquid. ${ }^{1} \mathrm{H}$ NMR $[\delta / \mathrm{ppm}]$ $\left(300 \mathrm{MHz}, \mathrm{CDCl}_{3}\right) 1.26(\mathrm{~d}, 3 \mathrm{H}), 1.50(\mathrm{dd}, 1 \mathrm{H}), 1.77$ (dd, $1 \mathrm{H}), 2.49(\mathrm{~m}, 1 \mathrm{H}), 3.80(\mathrm{~d}, 2 \mathrm{H}), 7.50(\mathrm{~d}, 2 \mathrm{H}), 7.80(\mathrm{~d}, 2 \mathrm{H})$. ${ }^{13} \mathrm{C}$ NMR $[\delta / \mathrm{ppm}]\left(75 \mathrm{MHz}, \mathrm{CDCl}_{3}\right) 19.1,28.9,29.2,73.9$, $115.2,129.5,136.2,163.9 .{ }^{29} \mathrm{Si} \mathrm{NMR}[\delta / \mathrm{ppm}](100 \mathrm{MHz}$, $\left.\mathrm{CDCl}_{3}\right)-14.24$.
2.5. Synthesis of Ethyl 4-(2-Methyl-3-triethoxysilylpropoxy)ben zenesulfonate (STES). $3.2 \mathrm{~g}(6 \mathrm{mmol})$ of 4-(2-methyl-3-trichlorosilylpropoxy)benzenesulfonyl chloride, ethanol $1.6 \mathrm{~g}$ $(0.35 \mathrm{mmol})$, and pyridine $2.0 \mathrm{~g}(0.25 \mathrm{~mol})$ were added to hexane $50 \mathrm{~mL}$ and heated at $50^{\circ} \mathrm{C}$ for $6 \mathrm{~h}$. Hydrogen chloride pyridine salt was filtered, and the filtrate was subjected to condensation. Ethyl 4-(2-methyl-3-triethoxysilylpropoxy)benzenesulfonate (STES) was isolated by short silica gel column chromatography using chloroform as an eluent.

Yield: $2.5 \mathrm{~g}$ (61\%). Slightly yellow liquid. ${ }^{1} \mathrm{H}$ NMR $[\delta / \mathrm{ppm}]\left(300 \mathrm{MHz}, \mathrm{CDCl}_{3}\right) 0.75(\mathrm{~m}, 2 \mathrm{H}), 1.12(\mathrm{~d}, 3 \mathrm{H}, J=$ $6.9 \mathrm{~Hz}), 1.22(\mathrm{t}, 9 \mathrm{H}, J=6.9 \mathrm{~Hz}), 1.29(\mathrm{t}, 3 \mathrm{H}, J=7.2 \mathrm{~Hz}), 2.22$ $(\mathrm{m}, 1 \mathrm{H}), 3.86(\mathrm{q}, 6 \mathrm{H}), 3.92(\mathrm{~d}, 2 \mathrm{H}), 4.08(\mathrm{q}, 2 \mathrm{H}), 7.00(\mathrm{~d}$, $2 \mathrm{H}, J=9.0 \mathrm{~Hz}), 7.82(\mathrm{~d}, 2 \mathrm{H}, J=9.0 \mathrm{~Hz}) .{ }^{13} \mathrm{C}$ NMR $[\delta / \mathrm{ppm}]$ $\left(75 \mathrm{MHz}, \mathrm{CDCl}_{3}\right) .{ }^{29} \mathrm{Si} \mathrm{NMR}[\delta / \mathrm{ppm}]\left(100 \mathrm{MHz}, \mathrm{CDCl}_{3}\right)$ -46.37. MS (ESI) $m / z=420[\mathrm{M}]^{+}, 375\left[\left(\mathrm{M}-\mathrm{C}_{2} \mathrm{H}_{5} \mathrm{O}\right]^{+}\right.$.

2.6. Synthesis of Poly(3-(4-ethoxysulfonylphenoxy)-2-methylpropyl)silsesquioxane (SPES). Into a $100 \mathrm{~mL}$ four-necked flask, STES $2.10 \mathrm{~g}(5 \mathrm{mmol})$ and ethanol $0.46 \mathrm{~g}$ were charged. After cooling for $10 \mathrm{~min}$ using an ice bath, water and $6 \mathrm{~mol} / \mathrm{L}$ hydrochloric acid were added in the molar ratio of $\mathrm{HCl} / \mathrm{SPES}=0.1$ and stirred for $10 \mathrm{~min}$. After removing the ice bath, the solution was stirred for $10 \mathrm{~min}$ at room temperature. The flask was then heated at $80^{\circ} \mathrm{C}$ for $4 \mathrm{~h}$ with stirring to provide poly(3-(4-ethoxysulfonylphenoxy)-2-methylpropyl)silsesquioxane (SPES) as a highly viscous liquid.

2.7. Formation of Films. A 33\% THF solution of SPES was poured into a scale made from polytetrafluoroethylene and heated at $80^{\circ} \mathrm{C}$ for 3 days.

2.8. Measurement. ${ }^{1} \mathrm{H},{ }^{13} \mathrm{C}$, and ${ }^{29} \mathrm{Si}$ nuclear magnetic resonance (NMR) spectra were recorded by JEOL NM ECP300 or JNM ECP-500. Chloroform- $d$ was used as a solvent, and tetramethylsilane was used as an internal standard of chemical shift.

Fourier transformation infrared (FT-IR) spectra were acquired by JASCO FT/IR410. The $\mathrm{KBr}$ disk method and $\mathrm{CCl}_{4}$ solution method were utilized for solid and liquid samples, respectively.

Gas chromatography (GC) was performed by Shimadzu GC-14B. Injection temperature: $250^{\circ} \mathrm{C}$. Column temperature: $50-250^{\circ} \mathrm{C}\left(+20^{\circ} \mathrm{C} / \mathrm{min}\right)$. TCD temperature: $250^{\circ} \mathrm{C}$. Carrier gas: helium.

Gas chromatograph/mass spectroscopy (GC/MS) was performed by JEOL GCMate.

High-performance liquid chromatography (HPLC) was performed with a Shimadzu LC-6AD attached to a YMC guard column ODS-A $(50 \times 20 \mathrm{~mm})$ and two YMC ODSA5 $\mu \mathrm{m}$. Acetonitrile $(7 \mathrm{~mL} / \mathrm{min})$ was used as an eluent. Detector: RID-10A.

Gel-permeation chromatography (GPC) was performed with a Shimadzu LC-6AD attached to a Polymer Laboratory PL gel $5 \mu$ Mixed-D column. Tetrahydrofuran was used as an eluent. Detector: RID-10A. 


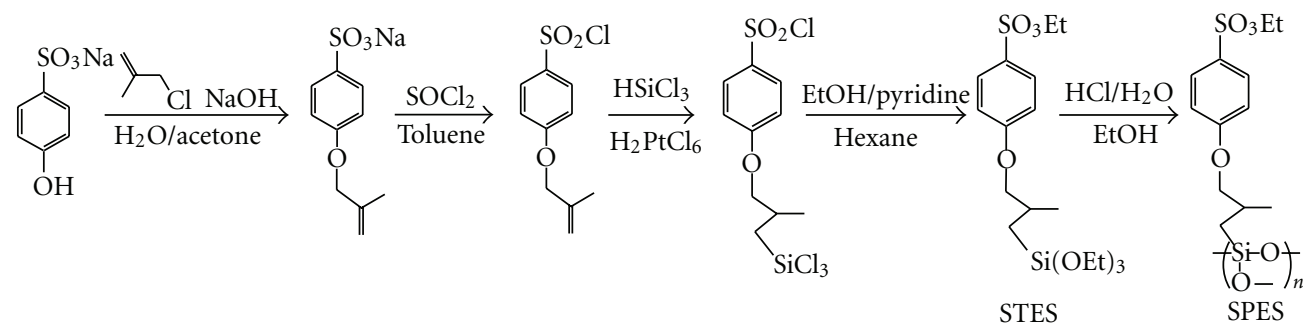

Scheme 1: Schematic figure for the synthesis of SPES.

TABLE 1: Results for the synthesis of SPES ${ }^{\mathrm{a}}$.

\begin{tabular}{|c|c|c|c|c|c|}
\hline \multirow[t]{2}{*}{ Number } & \multirow{2}{*}{$r\left(\right.$ molar ratio of $\left.\mathrm{H}_{2} \mathrm{O} / \mathrm{Si}\right)$} & \multirow[t]{2}{*}{ Yield (g) } & \multicolumn{2}{|c|}{$\mathrm{GPC}^{\mathrm{b}}$} & \multirow[t]{2}{*}{ Percentage ${ }^{c}$ of sulfonic acid/\% } \\
\hline & & & $M_{w}$ & $M_{w} / M_{n}$ & \\
\hline 1 & 1.0 & 1.77 & 2.000 & 1.2 & - \\
\hline 2 & 2.0 & 1.64 & 3.200 & 1.1 & - \\
\hline 3 & 3.0 & 1.51 & 4.500 & 1.1 & 7 \\
\hline 4 & 5.0 & 1.50 & 5.200 & 1.2 & 18 \\
\hline 5 & 6.0 & 1.54 & 5.800 & 1.5 & 32 \\
\hline 6 & 8.0 & 1.54 & 4.800 & 1.5 & 55 \\
\hline 7 & 10.0 & 1.50 & 4.400 & 1.3 & 61 \\
\hline 8 & 12.0 & 1.50 & 4.600 & 1.1 & 79 \\
\hline
\end{tabular}

${ }^{a}$ Scale in operation: STES $2.10 \mathrm{~g}(5 \mathrm{mmol})$. EtOH $0.46 \mathrm{~g}(10 \mathrm{mmol})$. Molar ratio: $\mathrm{HCl} / \mathrm{Si}=0.10$.

${ }^{\mathrm{b}}$ Calculated based on standard polystyrene.

${ }^{\mathrm{c} C a l c u l a t e d}$ based on the integral ratio of signals in ${ }^{1} \mathrm{H}$ NMR spectrum.

\section{Results and Discussion}

3.1. Synthesis of SPES. The synthesis of polysilsesquioxane having an arylsulfonate group as a side chain was planned by the hydrolytic polycondensation of trialkoxysilane. First, we planned the synthesis of ethyl 4(2-triethoxysilylethyl)benzenesulfonate by the hydrosilylation of ethyl 4-vinylbenzenesulfonate and triethoxysilane, which resulted in the formation of a mixture of ethyl 4(2-triethoxysilylethyl)benzenesulfonate and ethyl 4-(1-triethoxysilylethyl)benzenesulfonate. We therefore designed the structure of ethyl 4-(2-methyl-3-triethoxysilylpropoxy)benzenesulfonate as a target compound.

The synthesis of ethyl 4-(2-methyl-3-triethoxysilylpropoxy)benzenesulfonate was established by a four-step reaction from sodium 4-hydroxybenzenesulfonate dihydrate.

4- (2-Methyl-3 - trichlorosilylpropoxy) benzenesulfonyl chloride was synthesized by the hydrosilylation of 4-(2methyl-2-propenoxy)benzenesulfonyl chloride with trichlorosilane in the presence of chloroplatinic acid. This reaction proceeded gently to provide a unique product, 4-(2-methyl-3-trichlorosilylpropoxy)benzenesulfonyl chloride. This product was isolated by distillation under reduced pressure as a colorless liquid of high hydrolyzability. The formation of this compound was confirmed by the disappearance of signals corresponding to a vinylidene group in the ${ }^{1} \mathrm{H}$ and ${ }^{13} \mathrm{C}$ NMR spectra.

STES was synthesized by the reaction of 4-(2-methyl-3-trichlorosilylpropoxy)benzenesulfonyl chloride with ethanol. This reaction is one of the general procedures for replacing a chloro group with an ethoxy group: both chloro groups on silicon and sulfur were replaced with an ethoxy group in a one-step reaction. The formation of STES was confirmed by NMR and MASS analyses.

SPES was synthesized by the hydrolysis of STES in the presence of hydrochloric acid under a nitrogen stream. The results for the synthesis of SPES are summarized in Table 1 including the molecular weight and the percentage of sulfonic acid which were calculated based on the GPC analysis and the integral ratio of signals in the ${ }^{1} \mathrm{H}$ NMR spectrum of SPES, respectively. The progress of hydrolytic polycondensation of STES was confirmed by the increasing viscosity of the hydrolysis product. The yield of SPES decreased with an increase in the molar ratio of water to STES, which suggests the formation of SPES with high molecular weight. In addition, the molecular weight and the percentage of sulfonic acid of SPES increased with the increase of the molar ratio of water to STES. When the molar ratio of water to STES was set to be more than 6 , the molecular weight of SPES decreased in accordance with the degradation of the siloxane linkage by the sulfonic acid. SPES (number 2) was soluble in acetone, tetrahydrofuran, diethyl ether, and chloroform, and the solubility was independent of the molecular weight of SPES.

The ${ }^{1} \mathrm{H}$ NMR spectrum of SPES (number 2) is shown in Figure 1. The intensity of signals due to the ethoxy group in the ethoxysulfonyl group was decreased compared to that of the 2-methylpropyl group, which suggests the 


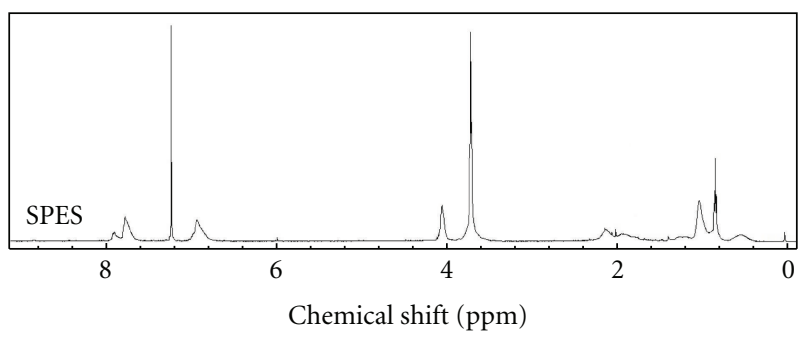

(a)

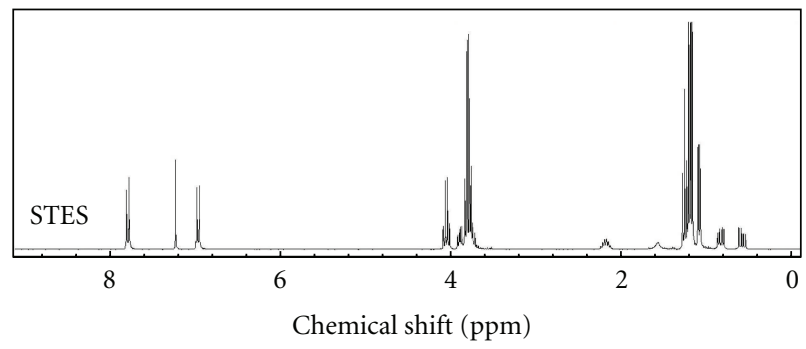

(b)

Figure 1: ${ }^{1} \mathrm{H}$ NMR spectra of STES and SPES (number 2).

hydrolysis of the ethoxysulfonyl group to form sulfonic acid. Additionally, the appearance of new signals due to a phenylene group at the lower field suggests the formation of sulfuric acid. The ${ }^{29} \mathrm{Si}$ NMR spectra of SPES (number 2) and SPTS are shown in Figure 2. The signal due to STES disappeared in the spectrum of SPES, and new signals appeared in the chemical shift areas ascribed to $T^{1}, T^{2}$, and $T^{3}$ unit structures. (The symbol $T^{n}$ denotes the unit structure as $\mathrm{RSi}(\mathrm{OSi})_{n}(\mathrm{OEt})_{3-n}(n=1,2,3$; R: 3-(4-ethoxysulfonylphenoxy)-2-methylpropyl group).) The appearance of signals due to $T^{1}, T^{2}$, and $T^{3}$ unit structures supports the formation of polysilsesquioxane. The degree of condensation was calculated based on the equation $A T^{3} /\left(A T^{1}+A T^{2}+A T^{3}\right)$, with $A T^{n}$ denoting the peak area of the unit structure $T^{n}$, as $46 \%$. Approximately half of the silicon atoms in SPES condensed to form the silsesquioxane structure.

3.2. Film Formation of SPES. SPES film was prepared by aging SPES (number 2) at $80^{\circ} \mathrm{C}$ for several days. A photograph of the SPES film is shown in Figure 3. SPES was a colorless liquid, and its film became brown with heating, which may have been due to the formation of a sulfonic acid group from the ethoxysulfonyl group. The thickness was approximately $0.1 \mathrm{~mm}$, and the film was brittle, easily broken into pieces when bended. The relatively low molecular weight and degree of crosslinking of SPES would cause this decrease in the film strength.

The film was colored by using an acid-functional dye: methyl red. The film was uniformly colored in red, which supports the formation of a sulfonic acid group by heating.

The thermogravimetric differential thermal analysis of thin film is shown in Figure 4. Exothermic peaks were found at $200-240^{\circ} \mathrm{C}$ and $600-640^{\circ} \mathrm{C}$ with weight loss and were

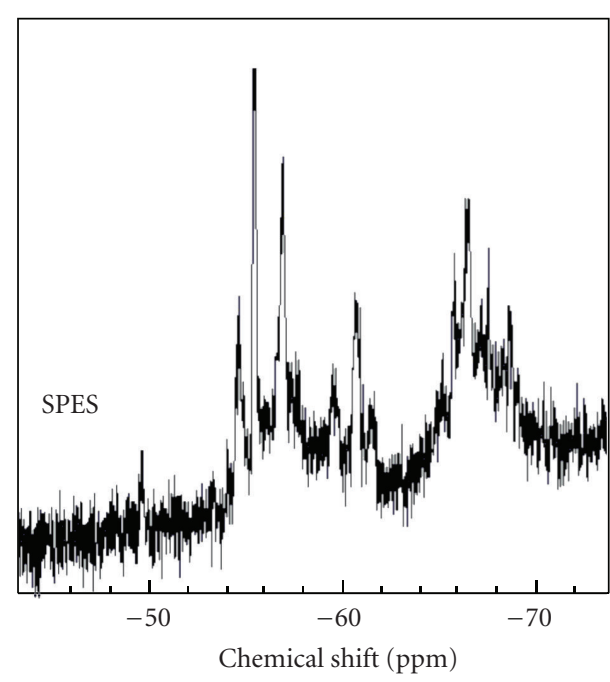

(a)

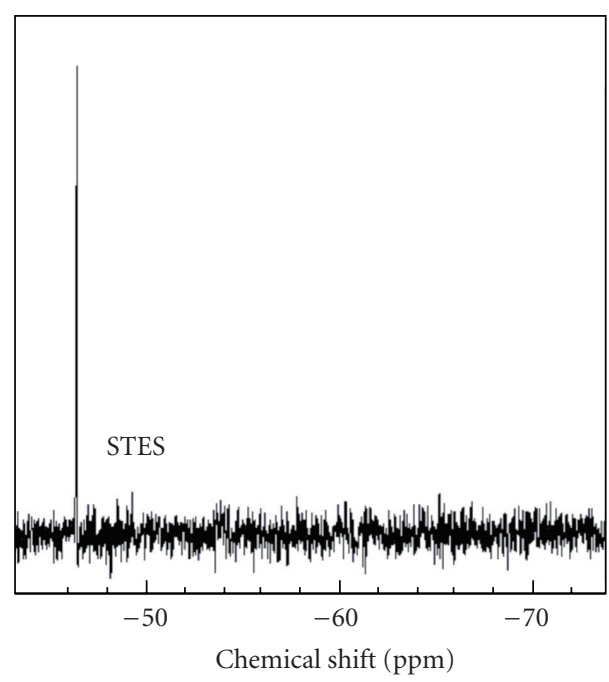

(b)

FIGURE 2: ${ }^{29} \mathrm{Si}$ NMR spectra of STES and SPES (number 2).

ascribed to the degradation of an ethoxysulfonyl group and organic component, respectively. The SPES film showed thermoresistivity up to $200^{\circ} \mathrm{C}$.

The film showed proton conductivity of $2 \times 10^{-2} \mathrm{~S} / \mathrm{cm}$ at room temperature.

\section{Conclusion}

Poly (3- (4-ethoxysulfonylphenoxy)-2-methylpropyl)silsesquioxane (SPES) was synthesized from sodium 4-(2-methyl2 -propenoxy)benzenesulfonate by a five-step reaction. The molecular weight of SPES was 2000-5200, reaching a maximum when the molar ratio of water was 6.0. The ethoxysulfonyl group was hydrolyzed when the molar ratio of water was greater than 3.0. The ratio of the $T^{3}$ unit was $46 \%$ when the molecular weight of SPES was 3200 . SPES film was prepared by heating SPES at $80^{\circ} \mathrm{C}$ for 3 days. The film 


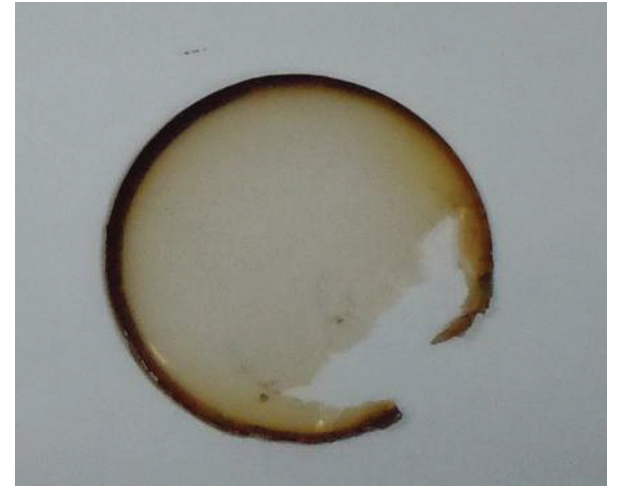

FIgURE 3: A photograph of the SPES film.

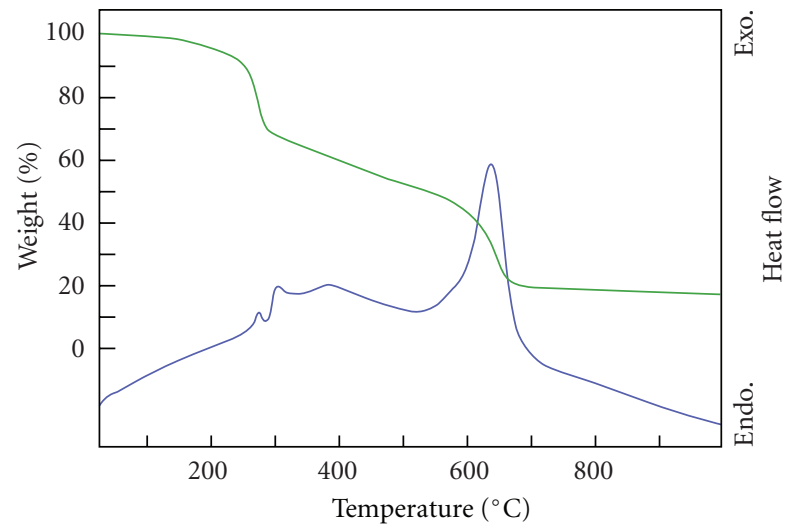

FIGURE 4: Thermogravimetric differential thermal analysis of SPES film.

was brown and brittle and showed thermal resistivity up to $200^{\circ} \mathrm{C}$.

\section{Acknowledgment}

This work was supported by a Grant-in-Aid for Scientific Research on Innovative Areas "New Polymeric Materials Based on Element-Blocks (no. 2401)" (24102008A02) of The Ministry of Education, Culture, Sports, Science and Technology, Japan.

\section{References}

[1] G. J. D. Kalaw, Z. Yang, I. H. Musselman, D. J. Yang, K. J. Balkus, and J. P. Ferraris, "Novel polysilsesquioxane hybrid membranes for proton exchange membrane fuel cell (PEMFC) applications," Separation Science and Technology, vol. 43, no. 16, pp. 3981-4008, 2008.

[2] T. Tezuka, K. Tadanaga, A. Hayashi, and M. Tatsumisago, "Proton-conductive inorganic-organic hybrid membrane prepared from 3-(2-aminoethylaminopropyl)triethoxysilane and sulfuric acid by the sol-gel method," Journal of the Electrochemical Society, vol. 156, no. 1, pp. B174-B177, 2009.

[3] M. Khiterer, D. A. Loy, C. J. Cornelius et al., "Hybrid poly electrolyte materials for fuel cell applications: design, synthesis, and evaluation of proton-conducting bridged polysilsesquioxanes," Chemistry of Materials, vol. 18, no. 16, pp. 3665-3673, 2006.

[4] K. Miyatake, T. Tombe, Y. Chikashige, H. Uchida, and M. Watanabe, "Enhanced proton conduction in polymer electrolyte membranes with acid-functionalized polysilsesquioxane," Angewandte Chemie, vol. 46, no. 35, pp. 6646-6649, 2007.

[5] C. S. Karthikeyan, S. P. Nunes, and K. Schulte, "Permeability and conductivity studies on Ionomer-polysilsesquioxane hybrid materials," Macromolecular Chemistry and Physics, vol. 207, no. 3, pp. 336-341, 2006.

[6] X. Li, Y. Song, M. Zhu, B. Liu, and Z. Jiang, "Preparation and properties of the POSS-containing composites as proton exchange membranes," Gaodeng Xuexiao Huaxue Xuebao, vol. 32, no. 8, pp. 1670-1672, 2011.

[7] S. H. Pezzin, N. Stock, S. Shishatskiy, and S. P. Nunes, "Modification of proton conductive polymer membranes with phosphonated polysilsesquioxanes," Journal of Membrane Science, vol. 325, no. 2, pp. 559-569, 2008.

[8] C. Chanthad, K. Xu, H. Huang, and Q. Wang, "Protonconductive polymer nanocomposite membranes prepared from telechelic fluorinated polymers containing perfluorosulfonic acid side chains," Journal of Polymer Science, Part A, vol. 48, no. 21, pp. 4800-4810, 2010.

[9] B. J. Liu, X. F. Li, M. M. Guo, C. Liu, L. Li, and Z. H. Jiang, "Synthesis and hybrid of a(4-phosphonic acid)phenylated poly(arylene ether sulfone)," Gaodeng Xuеxiao Huaxue Xuebao, vol. 31, no. 6, pp. 1081-1083, 2010.

[10] T. Gunji, Y. Suetaka, Y. Abe, S. Inagaki, and S. Fujita, "Synthesis of organic-inorganic hybrids from benzene-bridged polysiloxane," Kobunshi Ronbunshu, vol. 65, no. 6, pp. 416-420, 2008.

[11] T. Gunji, Y. Shigematsu, T. Kajiwara, and Y. Abe, "Preparation of free-standing films with sulfonyl group from 3mercaptopropyl(trimethoxy)silane/1,2-bis(triethoxysilyl)ethane copolymer," Polymer Journal, vol. 42, no. 8, pp. 684-688, 2010.

[12] A. B. Claryton, US Patent, 4897144. 

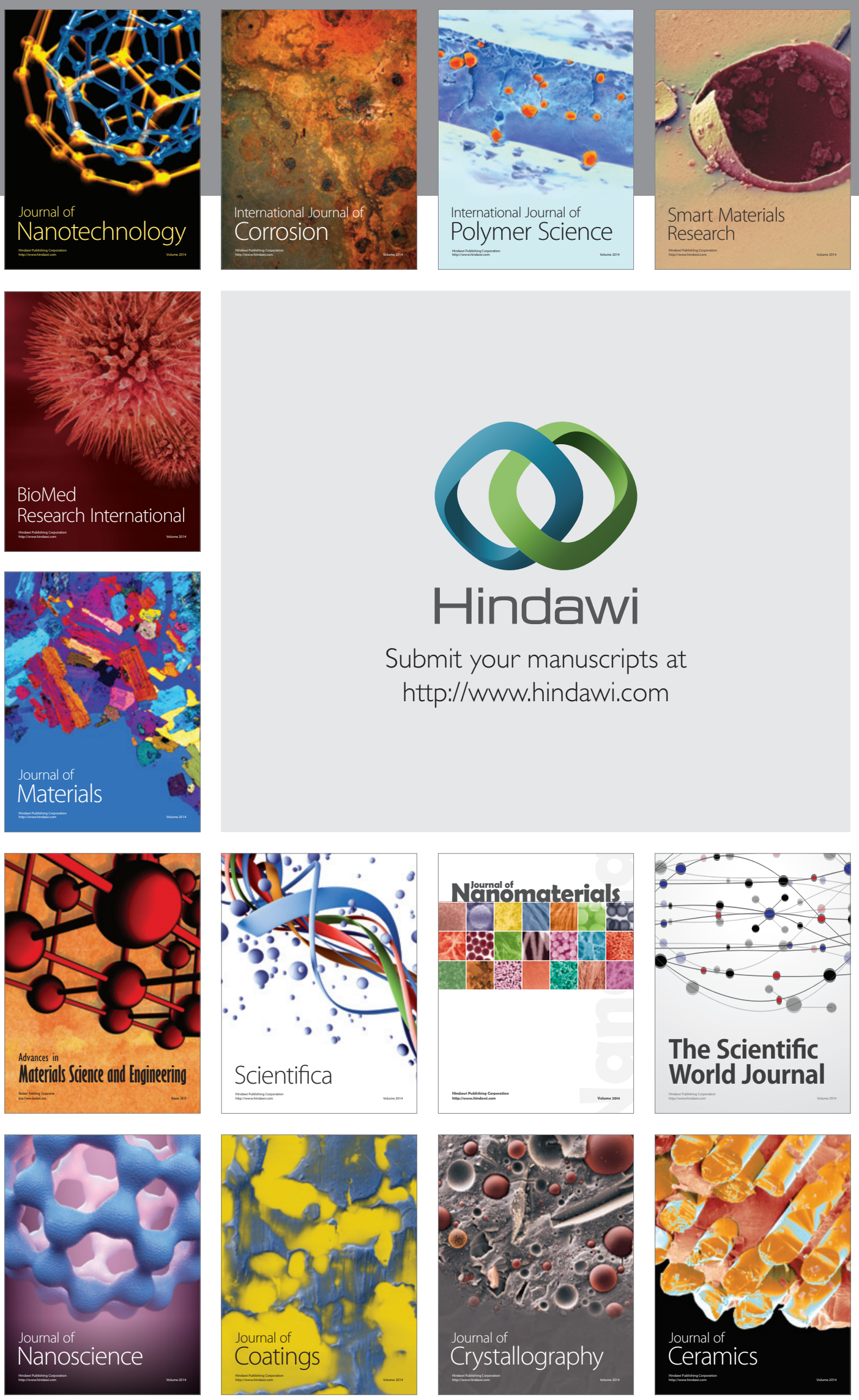

The Scientific World Journal

Submit your manuscripts at

http://www.hindawi.com

\section{World Journal}

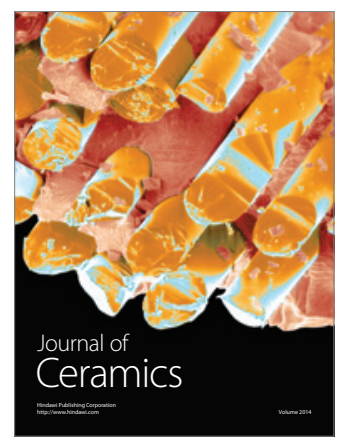

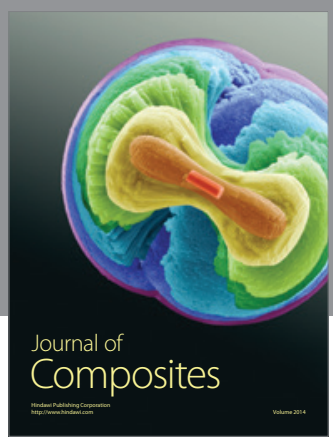
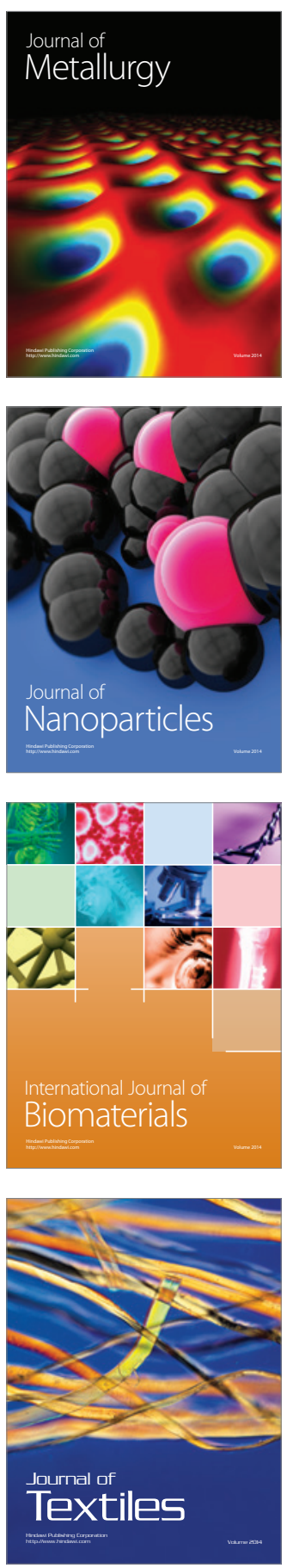